\title{
Correction to: Anatomy of sigma of a global predictive model for ground motions and response spectra
}

\author{
Carlo Cauzzi $^{1}$ (D) $\cdot$ Ezio Faccioli ${ }^{2}$
}

Published online: 4 December 2017

(C) Springer Science+Business Media B.V., part of Springer Nature 2017

\section{Correction to: Bull Earthquake Eng https://doi.org/10.1007/s10518-017-0278-4}

There are two inconsistencies in the paper which we hereby correct:

The y-axis label of Fig. 8 should preferably be " $\tau_{0, s, l}$ ".

The caption to Fig. 9 should read:

Fig. 9 Total $\tau_{\text {mech }}$ of CEA15 compared with the weighted standard deviation $\tau_{0, n}$ of the between-events residuals as explained in the text.

The original article can be found online at https://doi.org/10.1007/s10518-017-0278-4.

\section{Carlo Cauzzi}

carlo.cauzzi@sed.ethz.ch

1 Swiss Seismological Service (SED) at ETH Zürich, Zurich, Switzerland

2 Politecnico di Milano \& Studio Geotecnico Italiano, Milan, Italy 